\title{
Cambios neoliberales, contradicciones y futuro incierto de las metrópolis latinoamericanas
}

\author{
Neo-liberal changes, contradictions \\ and uncertain future of the Latin American metropolis
}

Emilio Pradilla Cobos [1]

\section{Resumen}

El neoliberalismo, un crecimiento económico cíclico y lento, su inserción subordinada en la acumulación capitalista mundial y la crisis social simultánea y prolongada, cambiaron las estructuras socioeconómicas y territoriales latinoamericanas. En este contexto, sus metrópolis sufren grandes mutaciones impulsadas por el capital inmobiliario-financiero dominante y crecen los conflictos territoriales. Los gobiernos nacionales y locales abandonaron su función interventora y reguladora, adoptando la facilitadora de la acción del capital privado; aquellos del "giro a la izquierda" siguieron similar rumbo, sin lograr los cambios esperados, causando la desilusión popular, que, sumada a la ofensiva del capital y la derecha, están produciendo su caída o desgaste. Una parte importante de la investigación urbana en la región, dependiente de teorías importadas, no aporta explicaciones acertadas ni políticas alternativas eficaces. Debemos seguir generando teorías adecuadas a nuestras formaciones sociales particulares, que respondan al incierto futuro urbano causado por la acumulación salvaje de capital.

Palabras clave: neoliberalismo; contradicciones territoriales; particularidades regionales; proyecto de ciudad; América Latina.

\begin{abstract}
In Latin America, neoliberalism, a cyclical economic growth, the region's insertion in the world's capitalist accumulation and the simultaneous social crisis have changed its socioeconomic structures. Its metropolises experience mutations driven by the dominant financialreal estate capital and territorial conflicts grow. Governments have abandoned their intervening and regulatory function, adopting the facilitator of private capital; those of the "turn to the left" have followed a similar course, without achieving the expected changes and causing popular disillusionment. This, together with the capital's and the Right's offensive, has caused the governments' erosion. Urban research, dependent on imported theories, does not provide accurate explanations or effective alternative policies. We must generate theories appropriate to our particular social formations that respond to the uncertain urban future caused by the wild accumulation of capital.
\end{abstract}

Keywords: neoliberalism; territorial contradictions; regional particularities; city project; Latin America. 
Las ciudades latinoamericanas han cambiado sustantivamente su estructura y funcionamiento a lo largo de los años transcurridos desde que la industrialización tardía y su correlato la urbanización acelerada iniciada en la década de los cuarenta del siglo $X X$, impulsaron la transformación de un subcontinente mayoritariamente rural hacia otro dominado por lo urbano. Estos procesos reales y los conflictos sociales que trajeron consigo, empujaron en los años sesenta a la formación de núcleos, entones muy reducidos, de académicos y funcionarios dedicados a su análisis y prospección.

En las últimas dos décadas del siglo $\mathrm{XX}$, las crisis económicas recurrentes y el abandono del patrón intervencionista de acumulación de capital imperante desde la $2^{\text {a }}$ Guerra Mundial, y su sustitución abrupta por el neoliberal, en medio de una nueva fase de la mundialización capitalista (Pradilla, 2009, cap. VIII), trajeron consigo otra oleada de cambios urbanos profundos, que aún continúan, y han hecho transitar a las ciudades latinoamericanas hacia las formas metropolitanas y a la constitución de extensas ciudades-región (Pradilla y Márquez, 2007), agudizado sus contradicciones y conflictos.

En esta nueva fase, hemos visto multiplicarse el número de investigador@s e investigaciones en muy diversos campos formales del conocimiento, que se han dedicado al análisis de los cambiantes procesos urbanos y sus conflictos. Las universidades de la región han abierto numerosos programas de licenciatura y, sobre todo, posgrado, orientados a la formación de profesionistas e investigador@s consagrados a las prácticas relacionadas con la producción del territorio, en particular el urbano, y la investigación científica de sus procesos. Ha surgido un gran número de grupos y centros de investigación, de redes nacionales, regionales y trasnacionales de investigador@s agrupados temáticamente, se han multiplicado los congresos y seminarios dedicados a muy diferentes temáticas territoriales y metropolitanas, y aparecen por todas partes revistas urbanas que ofrecen a los investigado@es la publicación de sus artículos, debidamente evaluados por pares internacionales.

En los países socio-económicamente dominantes, con mucho mejores condiciones económicas, sociales e institucionales para el trabajo académico que en los latinoamericanos, han florecido muy diversas propuestas teórico-metodológicas sobre los aspectos territoriales, que nuestros investigador@s leen ávida y presurosamente y un número importante de ellos utilizan profusamente en sus trabajos, mientras que pequeños pero significativos núcleos de investigadores críticos, trabajan en la comprensión de las particularidades de nuestros procesos territoriales urbanos, y en la formulación de teorías y métodos que expresen estas diferencias y propongan opciones propias para entender lo diverso en nuestras formaciones económico-sociales.

Es evidente que nos encontramos en medio de una vorágine de viejos y nuevos hechos urbanos, metropolitanos en particular, cuyas tendencias futuras no hemos logrado elucidar, cuyos necesarios cambios no acabamos de construir, pero que, por su incertidumbre y conflictividad social, exigen nuestra atención. A esto dedicamos este ensayo, que no pretende ser la lectura de una bola de cristal, sino una reflexión personal 
sobre el presente y los rumbos posibles para el futuro de las metrópolis latinoamericanas. Con este fin, nos apoyamos selectivamente en el trabajo pasado de investigación propio y de otros investigadores reconocidos de la región, y formulamos algunas hipótesis sobre lo vivido y lo que debemos desarrollar en el futuro, a manera de propuestas de trabajo a debate, en el sentido de los objetivos planteados para este número de la revista, conmemorativo de los 20 años de existencia del Observatório das Metrópoles.

\section{Más de tres décadas de cambios neoliberales}

Después de la crisis de 1982, los países latinoamericanos iniciaron, desigualmente en el tiempo y la intensidad del proceso, el tránsito desde el patrón de acumulación de capital con intervención estatal, vigente desde la $2^{\mathrm{a}}$ Guerra Mundial y que había servido a la tardía industrialización sustitutiva de importaciones, al neoliberal como nueva variante del patrón liberal clásico en la época de los grandes monopolios trasnacionales, promovido o impuesto por el Fondo Monetario Internacional, el Banco Mundial y las dependencias del gobierno estadounidense, encabezado por Ronald Reagan (1981-1989), y sus sucesores.

Este tránsito implicó la aplicación de un conjunto de políticas, conocido como el Consenso de Washington, que cambiaron la arquitectura y el funcionamiento de la acumulación de capital en las formaciones económico-sociales de América Latina, e incluyó: la lucha contra el déficit público por la vía de la reducción del gasto estatal, sobre todo el social; la reforma fiscal para reducir la progresividad impositiva y la tasa aplicada al ingreso de las empresas capitalistas y sus perceptores; la desregulación de la vida económica y social para avanzar en la liberalización de la acción del capital privado; la privatización de la mayor parte de las empresas públicas construidas en el pasado con fondos aportados por los contribuyentes, y otros bienes comunes, en los diferentes ámbitos de la acción estatal; la liberalización del comercio y de los flujos y mercados de capitales a escala internacional; la minimización o eliminación de las condiciones aplicadas a la entrada de la inversión extranjera directa a los países y a las empresas localizadas en el territorio nacional; la reducción sostenida del salario directo, indirecto y diferido real de los trabajadores activos; las reformas laborales regresivas, incluyendo el debilitamiento de los sindicatos, la reducción de las prestaciones sociales y la desregulación y flexibilización de los mercados y contratos laborales internos; entre otras medidas (Offe, [1988] 1991, pp. 135 y ss.; Guillen, 1997, pp. 99-133; Pradilla, 2009, cap. II).

Aunque la reforma neoliberal inició llevada de la mano por las dictaduras militares o civiles que dominaban en el subcontinente en las décadas de los setenta y ochenta, continuó con los gobiernos democráticos liberales instaurados luego de intensas luchas de los ciudadanos que llevaron a la burguesía a abandonar los modelos autoritarios abiertamente represivos. Este proceso continúa hoy día, ya sea en oleadas de reformas sucesivas que dan continuidad y profundizan a las iniciales, ${ }^{1}$ bajo el impulso de los organismos multilaterales (Fondo Monetario Internacional 
(FMI), Banco Mundial (BIRF), Organización Mundial de Comercio (OMC), Organización de Cooperación y Desarrollo Económico (OCDE) basadas en, etc.), o en la reinstalación plena del neoliberalismo, contenido o mitigado por algunos gobiernos del "giro a la izquierda", cuando estos pierden las elecciones o son depuestos por golpes parlamentarios 0 judiciales como en Argentina, Brasil y Ecuador recientemente.

Casi cuatro décadas después del inicio del cambio neoliberal, que prometió un continente integrado por el libre comercio, una economía sin crisis, un desarrollo socio-económico sostenido, el mejoramiento de las condiciones de vida, la eliminación de la pobreza y el ascenso al primer mundo de nuestros países, el balance aparece como poco halagador. Como ha ocurrido a lo largo de toda la historia del capitalismo, la economía latinoamericana ha avanzado entre ciclos de expansión y de recesión (crisis) o desaceleración aguda en 1982-1983, 1989-1990, 1995, 1999, 2001 2002, 2009 y 2015-2018, vaivenes agudos que no ocurrieron entre 1950 y 1980, cuando operaba el intervencionismo estatal a la manera keynesiana. Si entre 1950 y 1980, el crecimiento del Producto Interno Bruto (PIB) regional había sido, en promedio anual, superior al 6\%, entre ese año y 2016 ha sido notoriamente inferior al 3\%. Estas cifras invalidan la tesis neoliberal del crecimiento sostenido y sin crisis (Pradilla, 2009, pp. 312 y ss.; Cepalstat, 2017).

Uno de los factores de este débil crecimiento económico ha sido la desindustrialización relativa prematura que, según Salama (2012), ha ocurrido en los países latinoamericanos, en particular en los más industrializados (Argentina, Brasil, México), durante el período neoliberal, que ha llevado a la pérdida del sector más dinámico de la economía, que más y mejor empleo genera, ${ }^{2}$ con mayor productividad laboral, y que produce bienes exportables actuando en sentido positivo en la balanza comercial y de pagos del país. La desindustrialización ha acentuado la terciarización de la economía, en particular la urbana, con la característica específicamente latinoamericana del predominio en ella del empleo de subsistencia o precario conocido como informal (Márquez y Pradilla, 2008; Castillo y Pradilla, 2015). Como veremos luego, la desindustrialización y la terciarización han ocurrido sobre todo en las grandes metrópolis del subcontinente, en particular en las más industrializadas, donde se concentró la industria en el período de la posguerra.

En los años transcurridos del siglo $X X I$, la desindustrialización ha estado dialécticamente articulada a la reprimarización de las economías latinoamericanas, la cual, en la búsqueda de divisas abundantes y de fácil obtención derivadas del incremento de la demanda internacional y los precios altos de las materias primas agropecuarias y minerales, ha significado el retorno a su extracción, producción y exportación masiva. Entre 1981-1982, el porcentaje de exportaciones de productos primarios sobre el total de las efectuadas por América Latina y el Caribe fue de 51,5\%, descendió en 1998-1999 a 26,75\%, para elevarse nuevamente a 42,4\% en 2010 (Herreros y Durán, 2011, ver Gráfico 1), a lo cual habría que añadir las exportaciones de manufacturas de recursos naturales que fueron respectivamente de $25,5 \%, 18,4 \%$ y $17,7 \%$. La investigación y el debate sobre el 


\section{Gráfico 1 - América Latina y el Caribe: distribucción de las exportaciones totales} según intensidad tecnológica, 1981-2010

(En porcentajes del total)

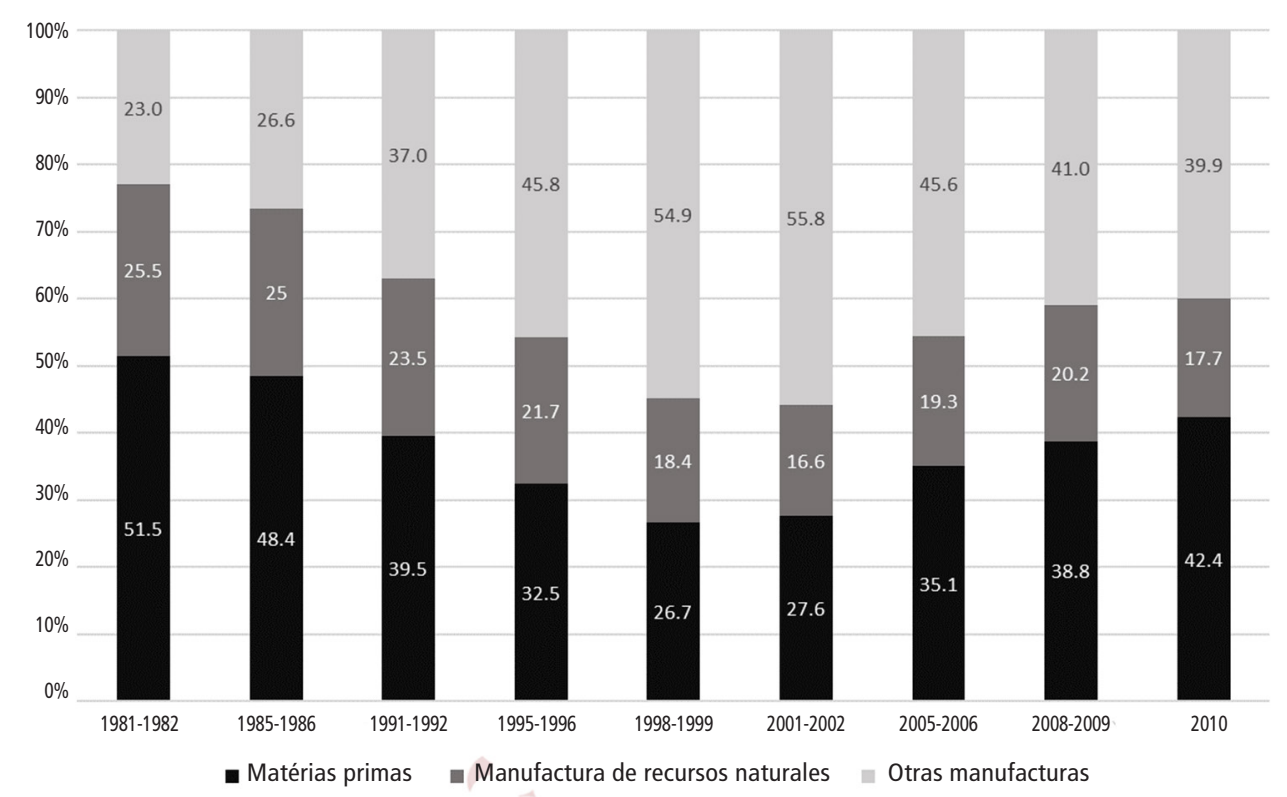

Fuente: Comisión Económica para América Latina y el Caribe, a partir de información oficial de los países. Base de datos de Naciones Unidas-COMTRADE. Tomado de Herreros y Duran, 2011.

tema y los impactos sobre la economía de la llamada "enfermedad holandesa", siguen aún, incluyendo autores que mantienen dudas sobre su existencia o importancia sobre todo en los grandes países como Brasil (Orozco, 2016).

Este boom ha empujado hacia el extractivismo generalizado de recursos naturales renovables y sobre todo no renovables, realizado fundamentalmente por empresas trasnacionales, regresando la historia hacia finales del siglo XIX, época de enclaves imperialistas, mineros y agrícolas, y gobiernos oligárquicos (Manrique, 2006, caps. XI y XII), pues sus características son inequívocamente regresivas con respecto a la industria manufacturera: tiene escasos vínculos con el resto de la economía, es poco generador de valor agregado, no diversifica la producción, crea empleos poco estables y temporales, los remunera con salarios más bajos que la media nacional, destruye la naturaleza con prácticas como la minería a cielo abierto y el "frackimg", agota rápidamente los recursos naturales sobre todo los no renovables incluyendo el agua, se le asocia con el despojo de bienes como la tierra, los bosques y el agua a las comunidades indígenas y campesinas y modifica profundamente sus territorios 
con grandes infraestructuras, y beneficia fundamentalmente al capital financiero y no a las fracciones productivas locales (Agencia de noticias U. N., 2014).

La escasa generación de empleo, una característica histórica del capitalismo latinoamericano que se ha acentuado con el acelerado cambio tecnológico en los procesos de producción, intercambio de bienes y servicios y la administración pública, arroja a masas crecientes de la población económicamente activa hacia la superpoblación relativa y el ejercito industrial de reserva (EIR) que debe sobrevivir mediante actividades de subsistencia conocidas ideológicamente como "informales" (Castillo y Pradilla, 2015). Actualmente, un $46,6 \%$ de la Población Económicamente Activa (PEA) latinoamericana y caribeña labora en actividades "informales", oscilando entre $30,7 \%$ en Costa Rica y 73,6\% en Guatemala. Entre los países más "desarrollados", en Brasil el $36,5 \%$, en Argentina el $46,8 \%$, y en México el $53,8 \%$ de la PEA nacional está en esta situación (Casabon, 2017).

El desempleo estructural, la gran masa de superpoblación relativa y EIR, sus pésimas condiciones laborales y de ingresos de subsistencia y la ausencia de seguridad social y otras prestaciones sociales, así como los bajísimos salarios que recibe el conjunto de los trabajadores asalariados de la región, sustancialmente reducidos en sus formas directa e indirecta y diferida, como política explícita durante el período neoliberal, han hecho que las multimillonarias sumas presupuestales gastadas por los gobiernos en programas asistencialistas, a la manera de los recomendados por el Banco Mundial, hayan sido ineficaces para reducir durablemente la pobreza moderada y la extrema: después de una disminución significativa entre 2002 y 2014 , desde entonces han vuelto a aumentar en porcentaje y en cifras absolutas para ubicarse en 2017 en 30,7\% y 10,2\%, y 187 y 67 millones de personas (Cepal, 2018, p. 88).

En la región seguimos enfrentando una crisis social de grandes proporciones, que parece contradictoria con la tasa de crecimiento del PIB, que aunque baja $(2,73 \%$ anual promedio entre 1990 y 2016), es positiva y muestra que el proceso de acumulación de capital continúa (Cepalstat, 2018); lo que queda claro es que el neoliberalismo ha incumplido sus promesas a la población, aunque no a los perceptores de ganancias, en especial a los empresarios trasnacionales, ya que la desigualdad multiforme es el signo de la época y la región, y es reconocida reiteradamente por la ONU-Cepal a pesar de ser una entidad gubernamental: desigualdad del desarrollo económico nacional, regional y urbano; profunda desigualdad en la distribución del patrimonio y el ingreso entre sectores sociales; desigualdad en el acceso a la vivienda y los servicios públicos; desigualdad y segregación en la apropiación de los territorios urbanos, etcétera (Jordán, Riffo y Prieto (coords.), 2017; Montero y García (eds.), 2017).

\section{Las contradicciones de las metrópolis latinoamericanas de hoy}

En anteriores trabajos hemos presentado las características fundamentales de las metrópolis latinoamericanas de hoy, resultantes de 
los procesos territoriales producidos por el despliegue histórico del capitalismo y por su acentuación en el patrón neoliberal de acumulación de capital vigente desde los años ochenta y la etapa de mundialización a la que ha dado lugar (Pradilla, 2009, cap. VII; Pradilla, 2014). Resumiremos estas características poniendo énfasis en la desigualdad y la combinación de formas económicas, sociales y físicas que constituyen su totalidad, y las contradicciones de naturaleza territorial que enfrentan a los actores metropolitanos.

América Latina se acerca cada vez más a la urbanización generalizada y casi total, aunque aún se mantienen grandes diferencias entre países y regiones (Pradilla y Márquez, 2007, cuadro 9, p. 258; Jordán, Riffo y Prieto (coords.), 2017; cap. I, 19 a 38, y cap. III, cuadro III.I, p. 78; Montero y García (eds.), 2017, p. 11), como efecto, fundamentalmente, del crecimiento demográfico natural -a la baja- de las grandes ciudades, y de la continuidad de la migración campo-ciudad, que se mantiene desde 1950 hasta ahora debido a la mayor tasa de crecimiento de la población rural que la urbana lo cual se expresa en una masa disponible para migrar empujada por las condiciones de atraso y pobreza del campesinado imperantes aún en el campo latinoamericano (Pradilla, 2009, cap. VI; Jordán, Riffo y Prieto (coords.), 2017, cap. III, 76-78), las cuales se trasladan del ámbito rural al urbano, donde engrosan la masa de trabajadores "informales", de ocupantes irregulares de terrenos y autoconstructores de vivienda o de inquilinos en la densificación de las viejas áreas populares.

Debido al crecimiento demográfico, se forman extensas ciudades-región, las grandes metrópolis continúan su crecimiento, nuevas ciudades viven procesos de metropolización y pequeñas concentraciones se convierten en ciudades medias. El ritmo de urbanización rápida iniciado en los años treinta del siglo XX, se distingue significativamente del seguido por las ciudades europeas y estadounidenses en su fase de expansión durante el siglo XIX, tanto en lo cuantitativo como en lo cualitativo (Pradilla, 2009, cap. I). A pesar de esta constatación, las organizaciones políticas y los gobiernos de turno, salvo contadas excepciones como a inicios del gobierno de Luiz Inácio Lula da Silva en Brasil (Maricato, 2015), han otorgado poca o nula importancia a la cuestión urbana en sus políticas nacionales.

Las metrópolis, en particular las capitales nacionales donde se concentró la manufactura en el período de la industrialización sustitutiva de importaciones (1930-1970), son componentes de gran importancia cuantitativa y cualitativa en la desigualdad regional del desarrollo que caracteriza a Latinoamérica y el Caribe hoy (Jordán, Riffo y Prieto (coords.), 2017, mapa II.1, p. 42). Ello ocurre a pesar de la situación regresiva que enfrentan las economías metropolitanas, las cuales han cambiado sustancialmente pues el rumbo que han tomado desde 1980, es el de la desindustrialización y la terciarización, que para diversos autores constituye el tránsito inevitable y positivo hacia una nueva etapa de desarrollo, la "revolución terciaria", pero que significa realmente la pérdida de dinamismo económico y de la mayor fuente de creación de empleo estable y adecuádamente remunerado con protección social, la causa de la caída de la productividad laboral media y un factor del surgimiento de un déficit de la 
balanza comercial urbana (Márquez y Pradilla, 2008; Orozco, 2016). Ahí encontramos una de las causas de la "informalización" de las metrópolis, otra particularidad histórica de nuestra región.

La desindustrialización absoluta y/o relativa y la correlativa terciarización "informalizada" de las economías metropolitanas, han acentuado los procesos nacionales ya señalados anteriormente (Márquez y Pradilla, 2008; Montero y García (eds.), 2017, p. 39), y liberado grandes superficies de terrenos urbanos ocupados antes por la industria, y ahora por megaproyectos terciarios y de vivienda de lujo, que en el mismo proceso reconstruyen las áreas antes usadas por las viviendas precarias de sus trabajadores a los cuales desalojan mediante la vía del mercado u otras prácticas menos apacibles. El conflicto enfrenta crecientemente a los trabajadores desalojados y a otros sectores de vecinos de las áreas renovadas cuya habitabilidad es destruida, contra el capital inmobiliario-financiero y los gobiernos locales que realizan la "renovación urbana" o la facilitan (Pradilla, 2016).

Una parte significativa ${ }^{3}$ del crecimiento de las actividades terciarias urbanas, está representada por prácticas precarias de subsistencia (informales), en particular el comercio en la vía pública, el sexo servicio, los choferes y guardaespaldas, el servicio personal de transporte, los lustrabotas y la mendicidad, cuya presencia callejera es visible en mayor o menor medida según la ciudad, dando lugar a un circuito económico mercantil simple de abasto de subsistencia de los sectores populares. Una parte de ellos subsiste mediante la vende a bajo precio de sus mercancías y servicios, y otra parte los adquiere para garantizar su reproducción con sus bajos ingresos y salarios. Múltiples contradicciones sociales urbanas se anudan en los ámbitos públicos de despliegue de las actividades de subsistencia, entre sus actores, los comerciantes y prestadores de servicios "formales", los transeúntes, automovilistas y transportistas cuya movilidad se ve limitada, los usuarios de lo público para su recreación y los agentes de la gestión urbana (Márquez y Pradilla, 2017).

Otra parte creciente de la superpoblación relativa ha tomado el camino de la delincuencia individual, en pequeñas bandas o como sicarios de grandes organizaciones delictivas dedicadas al narcotráfico mayor e internacional, la venta de drogas al menudeo, el secuestro, la trata y venta de personas para el sexo servicio o el trabajo esclavo, el contrabando, el robo de vehículos, combustibles y a personas 0 domicilios, y otras formas de violencia que han convertido a muchas regiones y ciudades del continente en territorios inseguros y campos de batalla entre los agentes del orden, los ciudadanos y los actores de la violencia. Nuestras ciudades aparecen siempre ocupando los primeros lugares en los rankings de las más violentas del mundo (Valenzuela, 2016; Valenzuela (coord.), 2011). Aunque sus ingresos, por obvias razones, pueden ser cuantiosos, la vida de estos "trabajadores" está permanentemente en juego.

En las últimas décadas, hemos asistido en varias $^{4}$ de las metrópolis latinoamericanas, a un cambio sustancial en la lógica de estructuración del sistema territorial de soportes materiales (Pradilla, 1984, cap. I): la formación de una trama de corredores urbanos terciarios, como 
concentraciones lineales sobre los ejes de flujos materiales (personas, vehículos y mercancías), de centros comerciales, comercios y servicios individuales, oficinas corporativas, inmuebles mixtos, viviendas de lujo "autosuficientes" 5 y otros nuevos soportes urbanos producidos por el gran capital inmobiliario-financiero trasnacionalizado, que han desplazado las funciones de centralidad urbana que antes cumplía el viejo centro comercial y de negocios expandido, que en la actualidad no puede ya cumplirlas debido a la gran expansión periférica de la ciudad ocurrida durante los años de urbanización rápida y metropolización (para el caso de la ZMVM, ver Pradilla (coord.), 2016, cap. 6).

Ante la desindustrialización en curso en las metrópolis, la industria de la construcción ha tomado su lugar como sector productor de valor y plusvalía, como refugio de acumulación para los capitales sobreacumulados tanto en las economías locales, en los países petroleros gracias a los altos precios del crudo, como en los países hegemónicos del capitalismo y su flujo a través del libre mercado de capitales. El capital financiero, cuya paulatina penetración en las economías latinoamericanas se hizo notoria durante el siglo XIX, luego de las guerras de independencia, y continuó durante todo el $X X$, ha llegado a fundirse con el capital inmobiliario y dominarlo debido a las características estructurales de su proceso de producción e intercambio (Pradilla, 2013), y hoy decide qué, donde, cuando y para quién se produce o reproduce lo urbano. El interés común, colectivo, que debería regir los procesos urbanos dada su naturaleza, siempre en el discurso de los políticos de turno, ha sido sustituido por las "razones del mercado urbano" y su actor dominante: el capital financiero y sus múltiples prácticas especulativas, sobre todo con la propiedad del suelo, y sus movimientos territoriales abruptos y desequilibrantes.

La población de bajos ingresos, despojada y expulsada de las áreas urbanas de más antigua producción por las acciones directas del capital inmobiliariofinanciero, por el incremento de las rentas del suelo y los impuestos territoriales (Jaramillo, 2009), o por los mecanismos del mercado, para llevar a cabo los procesos de reconstrucción urbana mediante las nuevas formas arquitectónicas, sigue ocupando irregularmente terrenos periféricos o reservas naturales y autoconstruyendo sus viviendas, 0 densificando en extensión y/o altura, las áreas ocupadas hace décadas, sirviendo así al capital para mantener bajos los salarios.

En las metrópolis latinoamericanas, la modernidad formal y material de la arquitectura y el urbanismo "posmodernos", aplicada en las múltiples obras del gran capital inmobiliario-financiero nacional y trasnacional, asumidas y festejadas como íconos de "desarrollo y competitividad urbana" por los gobernantes de turno, contrastan y se oponen abiertamente con las históricas y mayoritarias formas de subsistencia de los sectores populares, en continua interacción y conflicto que niegan toda posible explicación dualista del tipo castellsiano de "dos ciudades", y es mediatizado por el discurso gradualista de los gobiernos locales.

Los centros históricos de las metrópolis, sobre todo los de aquellas que datan del período colonial, poseedoras de una mayor riqueza de patrimonio arquitectónico, han sido "revitalizados" y "puestos en valor", 
convertidos en ocasiones en verdaderos escenarios teatrales para el disfrute de los visitantes extranjeros y la acumulación de capital del sector turístico trasnacional, ${ }^{6}$ que en muchos casos mantiene el manejo de los recursos monetarios por fuera de los circuitos locales. Estas acciones son planteadas como políticas públicas prioritarias por los organismos multinacionales y adoptadas por los gobiernos nacionales y locales como otra tabla de salvación de las economías metropolitanas ante la pérdida de dinamismo, pero solo dejan en manos de los sectores locales de pequeños y medianos emprendedores una muy limitada derrama de ingresos. Es recurrente que estas actividades sean centro del debate $y$, aún, del conflicto entre actores sociales debido a los impactos destructivos que tiene el turismo y las empresas que lo explotan, sobre el patrimonio arquitectónico y el ambiental urbano-regional, desde la etapa de construcción de sus soportes materiales.

El crecimiento demográfico de las metrópolis que continúa, aunque a menor ritmo que en el período de urbanización y metropolización aceleradas (1930-1980), su impacto sobre el incremento de la vivienda y los servicios públicos y privados que las acompañaron, y la relocalización periférica de diversas actividades urbanas como parte de su "modernización" reciente, se han combinado para mantener la expansión física metropolitana (Pradilla, 2015; Montero y García (eds.), 2017, p. 53). La dispersión periférica ha resultado de la acción combinada y desigual de: a) los actores de altos ingresos con sus fraccionamientos cerrados, campos de golf, unidades campestres, etcétera; b) los conjuntos de vivienda "de interés social", construidos por el sector inmobiliario-financiero privado en función de la nueva política pública de vivienda, una de cuyas características es la localización en la periferia lejana para obtener terreno a bajo precio (Pradilla, 2015); c) los proyectos de vivienda promovidos directamente por las instituciones vivienderas del Estado; d) el habitat de subsistencia de los sectores urbanos más pobres en terrenos irregularmente ocupados y viviendas autoconstruidas y/o autogestionadas, que aún continúan produciéndose a pesar de las acciones represivas de los gobiernos locales; y e) la localización periférica o interurbana de unidades operativas del capital industrial, comercial o de servicios. En el caso del habitat popular, esto ocurre aunque los sectores de bajos ingresos hayan buscado resolver la necesidad de vivienda sin enfrentar la represión, sin alojarse a grandes distancias de sus posibles empleos, y que los propietarios $u$ ocupantes en los ámbitos receptores, obtengan un ingreso adicional de subsistencia mediante la saturación de los terrenos o la construcción en altura, en los límites permitidos por las estructuras precarias de la vivienda existente, en las áreas "irregulares" producidas a mediados del siglo XX.

El resultado ha sido que entre 1990 y 2014, la densidad urbana cayera en la mayoría de las ciudades latinoamericanas analizadas por los investigadores de la Cepal: Sao Paulo, Ciudad de México, Buenos Aires, Santiago, Quito, Guadalajara, Curitiba, Florianópolis, entre otras, y solo aumentó en Bogotá, Belo Horizonte y Tijuana (Jordán, Rifo y Prieto (coords.), 2017, p. 33). Sin embargo, esta dispersión tiene poco que ver con la que ocurre en las periferias de las ciudades 
europeas (Demateis, 1998), por su presencia histórica en el caso anglosajón y su naturaleza de proceso reciente de ubicación de la clase media y alta en el caso de las ciudades mediterráneas, mientras que en general en las ciudades latinoamericanas tiene como componente fundamental la urbanización irregular popular de subsistencia, y sigue un ciclo, descrito por Duhau y Giglia, de expansión, consolidación por densificación de los intersticios, y posterior expansión (Duhau y Giglia, 2008, p. 216; Pradilla, 2015).

La expansión poblacional y su dispersión física, el aumento de la complejidad de las actividades metropolitanas, la agresiva política de mercado de las trasnacionales automotrices y las presiones de las empresas constructoras nacionales y trasnacionales, han empujado a los gobiernos locales a aplicar una continua política de reestructuración de la movilidad metropolitana en función del automóvil particular mediante la construcción de autopistas urbanas, túneles, vías rápidas elevadas, distribuidores viales, puentes, etcétera, mediante concesiones a largo plazo, o Alianzas Público-Privadas con el capital constructor y cobro de peaje a los usuarios (Montero y García (eds.), 2017, p. 54); y aunque han desarrollado sistemas novedosos de transporte público como el BRT, estos han tenido un lento crecimiento, son insuficientes ante la demanda, y siguen maniatados por la saturación vial generada por el automóvil. La movilidad motorizada entra en una continua contradicción con los peatones-transeúntes y los usuarios de otros medios no motorizados, aún en las ciclo-pistas improvisadas al vapor por las autoridades en una estrecha y saturada vialidad, que se materializa en las estadísticas de accidentes mortíferos.

La segregación urbana sigue profundizándose en función de la desigual distribución de la riqueza y los ingresos de los distintos sectores sociales (Jordán, Rifo y Prieto (coords.), 2017, p. 64, gráfico II.10; Montero y García (eds.), 2017, p. 31), cuya concentración en Ecuador, Colombia, Chile, México y Brasil es mayor que en los países capitalistas desarrollados europeos y asiáticos, y en Estados Unidos; Argentina y Uruguay, los de menos mala distribución de la riqueza, solo son superados en la desigual distribución por Estados Unidos y Suráfrica. La segregación territorial determinada por los niveles de ingreso está reforzada por la desigualdad en el acceso cuantitativo y la diferenciación cualitativa de las infraestructuras y los servicios públicos, sociales y culturales que sirven como condiciones generales de reproducción de la población, crecientemente privatizados y mercantilizados en el neoliberalismo (Márquez y Pradilla, 2017), poco accesibles debido a los bajos salarios e ingresos o a la ausencia de ellos en las áreas periféricas de localización de sus viviendas.

La guetificación de las ciudades ha sido acentuada por dos fenómenos bipolares: de un lado, la multiplicación de barreas físicas construidas por los sectores de altos ingresos como unidades amuralladas, controladas por artefactos electrónicos y vigilantes armados, y por los gobiernos locales bajo la forma de vialidades confinadas que fragmentan y aíslan los territorios; y de otro, los territorios disputados y controlados por las bandas criminales que se multiplican en nuestras ciudades (Pires do Rio Caldeira, 2007; Valenzuela (ed.), 2011, entre otros). 
Las grandes ciudades contaminan su propio ambiente: el aíre con las emisiones de los millones de vehículos automotores que en ellas circulan, de las industrias con tecnologías obsoletas, de polvo, residuos industriales, materias fecales y otros contaminantes sólidos que el viento transporta; el agua con los aceites de los vehículos, el derrame de residuos líquidos de la industria, y las demás aguas negras inadecuadamente desechadas, que se filtran a los mantos acuíferos comúnmente usados para extraer agua que se suministra como potable a los consumidores; el suelo con la basura doméstica y los desechos industriales y hospitalarios que se depositan en tiraderos clandestinos y lugares inapropiados. Al mismo tiempo, las metrópolis son gigantescas contaminadoras del territorio circundante con miles de toneladas diarias de basura depositadas en tiraderos a cielo abierto 0 , aún, en enormes rellenos sanitarios; o las cuencas hidrográficas y los campos de cultivo del territorio circundante con millones de litros diarios de aguas negras no tratadas vertidas directamente a los ríos, cuyos contaminantes pueden regresar a los citadinos en los alimentos que producen. Finalmente, la expansión urbana, por negocio o por necesidad de subsistencia, devora anualmente con el crecimiento periférico cientos de hectáreas de tierras agrícolas y pecuarias, bosques, humedales, cuerpos de agua, áreas de preservación ecológica, etcétera (Montero y García (eds.), 2017, pp. 50-68). Todo ello ocurre debido a: la prioridad pública dada al automóvil particular como medio de transporte urbano y las vialidades para su circulación; las limitaciones presupuestales y tecnológicas para resolver adecuadamente la disposición final de desechos; las prácticas ilegales permitidas por la corrupción burocrática; la tolerancia de una legislación ambiental muy complaciente con el interés empresarial y muy alejada de aquel del conjunto de la sociedad; o la corrupción de los funcionarios públicos. La lucha de los movimientos ambientalistas durante las últimas décadas y la certeza científica sobre las graves implicaciones del cambio climático han hecho evidente esta contradicción, pero los gobiernos han respondido a ella con un discurso demagógico de la "sustentabilidad" más que con políticas eficaces y eficientes adecuadas a la gravedad de la situación.

Múltiples formas de la desigualdad social imperan en las ciudades latinoamericanas, incluida su más hiriente manifestación: la pobreza territorialmente concentrada (Montero y García (eds.), 2017, pp. 21 y ss.). En ellas se combinan contradictoria y contrastantemente, la economía mundializada materializada en las sedes de las trasnacionales y los monopolios nacionales asociados, y la más atrasada economía mercantil simple y de subsistencia. La opulencia y la pobreza extrema materializadas en las viviendas, los lugares de trabajo, de comercio y servicios, de recreación de las nuevas unidades de vivienda "autosuficientes" de los sectores de más altos ingresos, producidos por el gran capital inmobiliario-financiero, y los tugurios viejos y nuevos de los sectores populares en situación de subsistencia, irregulares y autoconstruidos, que Connolly caracteriza como "un paradigma latinoamericano" por su especificidad (Connolly, 2013).

En el proceso de cambio de las funciones del Estado en sus diferentes niveles (nacional, estatal, local), en su tránsito de interventor 
y promotor a facilitador subsidiario de la acción del capital, que formó parte de las reformas neoliberales, como elemento sustantivo de la desregulación de la vida económica y social, y debido al papel dominante que ha ido asumiendo el capital inmobiliario-financiero nacional-trasnacional en la producción y re-producción de la ciudad latinoamericana (Pradilla, 2013), la planeación urbana indicativa propia del anterior patrón económico, cuya ineficacia ha sido puesta en evidencia por muchos investigadores (Pradilla, 2009, cap. V), se diluyó y fue sustituida por la llamada "planeación estratégica", inspirada en la programación empresarial, entendida en la práctica como la sumatoria de grandes proyectos urbano-arquitectónicos privados y de infraestructura públicos y los mixtos realizados en Alianza Público Privada, así como, y sobre todo, por políticas urbanas pragmáticas orientadas a facilitar la inversión privada.

\section{Esperanzas frustradas y arremetida política del capital}

Este curso, con variantes más o menos significativas, pero no estructurales, ha sido seguido por las ciudades latinoamericanas de todas las escalas, de las pequeñas y medianas concentraciones hasta las grandes regiones urbanas, con mayor virulencia entre más complejas y significativas estructuralmente sean para la concentración, centralización y acumulación del capital. Los gobiernos nacionales y locales han adecuado y mantenido sus políticas urbanas para reproducir este curso, incluyendo aquellos que han formado parte del llamado "giro a la izquierda" o "marea rosa" latinoamericana, acentuada después del año 2000 y analizada por diversos autores (Manrique, 2006, cap. XXIV; Robinson, [2008] 2015, cap. 6; Palacio y Valenzuela (coords.), 2013; Gausseus, 2015; Carrión y Ponce (coords.), 2015).

A título hipotético, suponemos que los gobiernos "progresistas" latinoamericanos, a pesar del otorgamiento a los ciudadanos de nuevos derechos civiles, generalmente de corte democrático-liberal, o los múltiples programas sociales focalizados en los sectores más vulnerables, instaurados en países o ciudades, no han logrado diferenciar claramente sus políticas urbanas de las de los neoliberales debido a: a) las notorias diferencias de sus postulados ideológicos y sus políticas concretas que no han permitido una acción internacional unitaria y conjunta ante opositores unificados por los intereses del capital; b) que la concepción ideológica de los gobernantes y/o sus partidos se acerca más a la de un "neoliberalismo con rostro humano", que a la del anticapitalismo o el anti neoliberalismo de corte keynesiano; c) que las políticas puestas en marcha se han mantenido en el ámbito de las exigencias de los organismos multinacionales para mantener el acceso al crédito internacional; d) que las alianzas políticas con partidos o movimientos centristas con las que han llegado al poder les han impuesto compromisos con el statu quo neoliberal (Maricato, 2015); e) que consideran necesario no afectar a segmentos significativos del capital nacional o extranjero para mantenerse en el poder, no enfrentar su ataque abierto y lograr gobernar, sin intentar cambiar a la sociedad y/o la ciudad capitalista (Valenzuela, 2013). 
Todo indica que en lo que se refiere a las políticas urbanas en América Latina, podríamos aplicar a los gobiernos "progresistas" el título del libro de Gausseus (2015): "tomar el poder sin cambiar el mundo", pues fuera del otorgamiento de nuevos derechos civiles a los ciudadanos, la aplicación de limitadas políticas sociales asistencialistas, la introducción de prácticas de participación ciudadana democrática como el "presupuesto participativo" muy difundido, las consultas públicas y la rendición de cuentas, y el mantenimiento de la participación gubernamental en ciertos procesos urbanos, los numerosos gobiernos locales "de izquierda" que han aumentado notoriamente su número en la región después de 1995 (Carrión y Ponce, 2015, p. 38), no han emprendido procesos de cambio socio-económico o territorial sustantivos y estructurales.

Por lo anterior, los investigadores críticos en general mantenemos la caracterización de "neoliberales" también para las ciudades de los países donde ocurrió el giro, debido a la continuidad de las relaciones capitalistas neoliberales de producción en el territorio y la naturaleza de clase de los procesos urbanos que en ellas se han desarrollado durante esos períodos.

A pesar de lo limitado de los cambios en lo económico-social y lo territorial, el capital, en particular el monopolista nacional y trasnacional, y la derecha política latinoamericana iniciaron un contraataque hacia los gobiernos "progresistas" o "populistas" que dio lugar al triunfo en Argentina de Mauricio Macri en diciembre del 2015; a la destitución arbitraria de Dilma Rousseff en Brasil en agosto del año siguiente y en 2017 a la condena y encarcelamiento de Luis Inacio Lula da Silva, expresidente y pre-candidato con mucho apoyo popular para la elección del 2018, impidiéndole ser el candidato de su partido, dándole una mayoría al candidato de extrema derecha en la primera vuelta electoral $y$, posiblemente, en la $2^{a}$ vuelta definitiva. La elección de Lenín Moreno en 2017 en Ecuador que está marcando el abandono de las políticas de Rafael Correa y su "revolución ciudadana"; en Chile, los dos gobiernos de Sebastián Pinera (2010-2014 y 2018 en adelante) que marcaron el desgaste del gobierno del Partido Socialista iniciado en el 2000. En Venezuela, el gobierno chavista de Nicolás Maduro enfrenta una dura arremetida de boicot económico y de movilizaciones, que también ocurren en la Nicaragua de Daniel Ortega; y el futuro incierto del gobierno de Evo Morales en Bolivia, el país de la región más asolado por las dictaduras militares a lo largo de su historia, que se encuentra en entredicho al serle negada su discutible nueva reelección.

Aún falta mucho análisis objetivo, no condicionado por la militancia individual o la esperanza subjetiva, que nos permita hacer un balance de la experiencia "progresista" en el subcontinente. En especial, sobre el por que las masas urbanas no han sustentado y mantenido más activamente a estos "gobiernos progresistas", a pesar de haber obtenido beneficios de ellos como la ampliación de los derechos civiles y sociales, o la contención de las peores prácticas económico-sociales del neoliberalismo.

Posiblemente, la explicación la encontramos en la conjunción desigual de varias hechos que afectan la credibilidad de los ciudadanos y llevan a la desilusión de los 
sectores populares: las limitaciones políticoideológicas de los partidos "progresistas", sobre todo en lo que se refiere a la superación del capitalismo y, aún, de su forma neoliberal salvaje; la ausencia de un proyecto urbano que supere las contradicciones actuales; los compromisos de los partidos de gobierno con diversas fracciones del capital, que limitan sus políticas de cambio; el dominio de las prácticas liberales de la democracia política representativa entre los partidos progresistas y las masas populares, sin avanzar hacia formas para su participación directa; el mantenimiento de las prácticas depredadoras del capital nacional-trasnacional; la corrupción e impunidad que afecta también a los gobiernos y partidos "progresistas" en el poder; la perdida por las masas de la esperanza en el cambio ante la persistencia de la situación angustiante del desempleo, la pobreza, la ausencia de servicios públicos urbanos y la exclusión; el poder y penetración de las campañas publicitarias de la derecha y los empresarios en los medios de comunicación bajo su control; y las acciones de desestabilización económica, fuga de capitales, cierre de empresas y movilizaciones de boicot que afectan a las masas, agravando su situación objetiva.

No podemos predecir el futuro de las tendencias políticas nacionales en la región, y menos aún las de los gobiernos locales, sobre todo cuando el mundo se ve invadido por movimientos políticos de extrema derecha, nacionalistas, racistas, xenófobos, contrarios a la democracia liberal, los derechos humanos y, aún, al libre mercado neoliberal, que llegan al poder tanto en países desarrollados como atrasados; pero difícilmente podemos imaginar que se mantenga el "giro a la izquierda" por la vía de la democracia liberal, cuando las poblaciones ven frustradas sus esperanzas de cambio profundo, estructural, anti-capitalista o anti-neoliberal al menos, depositadas en los políticos auto proclamados "progresistas" 0 "de izquierda" que sin embargo mantienen el curso socio-económico neoliberal causante de su desempleo, su pobreza, su exclusión.

En los dos trabajos publicados por la Cepal, aquí multicitados (Jordán, Rifo y Prieto, (coords.), 2017; Montero y García (eds.), 2017), no se observan diferencias sustanciales en el curso seguido por las ciudades en los países gobernados por políticos y/o movimientos del "giro a la izquierda" y en los que se consideran conservadores, pues todos siguen, más o menos estrictamente, el curso marcado por las políticas urbanas neoliberales y los organismos multilaterales, por lo cual, luego de cerca de cuatro décadas de aplicación, no podemos esperar un cambio significativo de las tendencias en los procesos urbanos reales que nos señalan los autores cepalinos, y que hemos buscado analizar desde hace tiempo en nuestros trabajos (Pradilla, 1998; Pradilla y Márquez, 2007; Pradilla, 2014). Por tanto, no tenemos razones suficientes para ser optimistas sobre el futuro de las ciudades latinoamericanas y de la mayoría de sus habitantes afectados por las críticas tendencias aquí esbozadas, las cuales continuarán en las próximas décadas al no visualizarse cambios profundos en la esfera de lo político, ni manifestarse fuerzas populares organizadas en torno a un proyecto de cambio socio-territorial sustantivo.

No podemos fincar nuestras expectativas de cambio urbano en la aplicación por nuestros gobiernos de las propuestas de política de los 
organismos oficiales multilaterales a la manera de la Nueva Agenda Urbana (ONU-Habitat, 2017); las políticas planteadas por Habitat I y II, hace 40 y 20 años quedaron como letra muerta, y la NAU está repleta de declaraciones demagógicas, neologismos, adjetivaciones de la ciudad, ${ }^{7}$ y políticas homogeneizadas para todos los países de la tierra con la justificación de la "globalización" en su variante apologética, de un claro contenido capitalista neoliberal, pues mantener las acciones que generaron las contradicciones urbanas actuales no hará otra cosa que ampliarlas y profundizarlas.

\section{Un nuevo enfoque para analizar nuestra realidad}

Desde la colonización de América Latina por España y Portugal, hasta su independencia, en los territorios latinoamericanos se aplicaron las políticas impuestas por las Coronas Imperiales colonizadoras. Posteriormente, los políticos y los estados latinoamericanos, han sido tributarios de las políticas urbanas ${ }^{8}$ importadas desde los países hegemónicos del capitalismo en sus diferentes etapas: en el siglo XIX, de Francia e Inglaterra, potencias europeas distintas a sus antiguas colonizadoras; luego, de la nueva potencia hegemónica del capitalismo, los Estados Unidos de América; y desde la segunda posguerra mundial, de este y de los organismos multilaterales globales que han ido surgiendo y que controla: la Organización de Naciones Unidas (ONU) y sus distintos organismos sectoriales, en particular ONU-Habitat; el Fondo Monetario Internacional (FMI), el Banco Mundial (BIRF), el Banco Interamericano de Desarrollo (BID), la Organización de Cooperación y Desarrollo Económico (OCDE), la Organización Mundial de Comercio (OMC), etcétera, cada una desde su particular ámbito de intervención trasnacional. Desde 1976, los documentos emanados de las tres conferencias de ONU-HABITAT (Vancouver, Estambul, Quito), celebradas cada 20 años, se han convertido en "biblias" alabadas y recitadas doctamente, pero muy poco cumplidas por los gobiernos latinoamericanos signatarios. Este sometimiento formal en nuestro campo, forma parte de la situación de subordinación multifactorial, estructural, hacia las potencias capitalistas hegemónicas.

Los investigadores, por nuestra parte, según la orientación teórica personal, hemos sido tributarios, usuarios y dependientes de las teorías urbanas elaboradas en los países hegemónicos para explicar su propia situación territorial - regional y urbana -, sin tener en cuenta las características específicas y particulares de nuestras formaciones económico-sociales (Pradilla, 2010a; Duhau, 2013). Las razones de esta subordinación teórica son múltiples: las relaciones de dominación socio-económica, política y cultural internacional como determinante general a lo largo de la historia del capitalismo; las mejores condiciones de trabajo de los investigadores urbanos en los países hegemónicos, en particular en el aspecto económico, laboral y de libertad de creación, las cuales les permiten una mayor y mejor producción teórica; las limitaciones experimentadas en nuestra región por los frecuentes gobiernos dictatoriales o las poco desarrolladas democracias liberales; la debilidad de los aparatos editoriales nacionales, con frecuencia dominados por trasnacionales 
que publican y distribuyen presurosas la producción de autores internacionales pero no la de los latinoamericanos, editada casi siempre por editoriales universitarias locales sin distribución a nivel nacional e internacional; la limitada inversión en ciencia y tecnología, manejada por instituciones públicas que no reconocen directamente a nuestro campo de trabajo, que imponen ritmos cuantitativos de producción poco adecuados a la elaboración teórica, y cuyas políticas de evaluación, clasificación y apoyo a los investigadores, exigen la publicación en los idiomas de los países dominantes, no en los de nuestros países, y el uso de referencias teóricas y técnicas importadas y subordinantes; entre otras.

Por estas razones, que incluyen nuestra aceptación pasiva de la situación, las investigaciones que llevamos a cabo están infestadas de neologismos, anglicismos, galicismos, generalizaciones arbitrarias y homogeneizadoras, de "marcos teóricos" que no sirven de instrumentos de análisis, sino a los que sometemos con calzador nuestras especificidades territoriales, o que usamos como simple "introducción", o del recurso a citas "académicamente correctas" de los autores consagrados, pero poco útiles en el trabajo, etcétera (Pradilla, 2010a).

En esta "noche en que todos los gatos son pardos", pues la "globalización" todo lo homogeneiza aparentemente, ideológicamente, desaparecen todas las particularidades y especificidades de nuestras formaciones económico-sociales y nuestra región, modeladas por las determinaciones del colonialismo y la dominación imperialista homólogas a lo largo de la historia: el proceso de despojo de riquezas a la que han estado sometidas continuamente desde la conquista y su común inserción, como fuente, en el proceso histórico de acumulación originaria de capital y en sus formas posteriores más desarrolladas; la industrialización tardía y trunca, dominada por las trasnacionales; el intercambio mercantil desigual con las potencias capitalistas; el despojo y la depredación territorial en la reprimarización y el extractivismo en curso; la gran magnitud de la superpoblación relativa y el ejercito industrial de reserva sui generis; las masivas actividades de subsistencia "informales", generalizadas en nuestras ciudades; la persistencia de numerosas formas precapitalistas de producción e intercambio, combinadas a las capitalistas atrasadas 0 "modernas"; la pobreza dominante entre las masas trabajadoras; la urbanización acelerada, tardía y polarizada; la producción irregular y precapitalista mayoritaria del habitat popular urbano; la debilidad estructural de los estados y la presencia continua de dictaduras militares y democracias autoritarias limitadas; la poca fuerza de las políticas de regulación, intervención y control estatal en general y en lo territorial en particular; la dependencia política y de las políticas territoriales en relación con las potencias hegemónicas y sus organismos multilaterales, justificada por la "ayuda para el desarrollo"; las grandes limitaciones históricas de la producción de Condiciones Generales de Reproducción de las Formaciones Sociales (Pradilla, 1984, cap. II), estructurantes de lo urbano; etcétera (Márquez y Pradilla, 2016).

Debido a que somos formaciones sociales dominantemente capitalistas, la teoría general que explica este modo de producción "en estado puro", es válida 
para nuestros países; pero como ellas se han desarrollado desigualmente en relación a los países hegemónicos a los que se encuentran subordinadas, que su estructura socio-económica, política, cultural y, por tanto, territorial ha sido históricamente diversa, las teorizaciones de segundo nivel - regionales, elaboradas para explicar las formaciones sociales y territoriales dominantes no son adecuadas para explicar las nuestras.

Debemos, pues, recuperar, revisar, sistematizar y potenciar el trabajo fecundo, persistente durante décadas, algunas muy duras por la represión, de nuestros investigadores, para construir esa teoría urbana que nos permita explicar la historia propia, pasada y presente, de las ciudades latinoamericanas. A muestra memoria vienen muchos nombres que han aportado valiosos planteamientos teóricos en este sentido y que no mencionamos aquí para no correr el riesgo de olvidar algunos importantes. Sin embargo, en la compilación Teorías sobre la ciudad en América Latina, publicada en 2013, los autores de los ensayos que lo conforman, hicieron la recuperación de estos y de sus aportes en varios de los procesos más importantes de/en nuestra realidad urbana latinoamericana, cuya revisión nos ayudará en esta aventura del conocimiento (Ramírez y Pradilla (coords.), 2015). A partir de este acervo invaluable, integrado críticamente, podemos y debemos continuar la tarea de construcción de una teoría urbana latinoamericana.

Esta es una condición necesaria de la elaboración de políticas alternativas de cambio estructural real de los territorios y ciudades de nuestra región, como parte de proyectos de nación alternativos al capitalista y neoliberal, o a las caricaturas del cambio. No es un problema nacional producto de un nacionalismo trasnochado, sino una necesidad objetiva de correspondencia entre la realidad, su explicación teórica y la propuesta de su transformación. Es nuestra obligación, pues es nuestra práctica social declarada, cuando nos hacemos eco de las necesidades de los sectores populares y solicitamos la transformación estructural de las condiciones de vida en nuestras ciudades y metrópolis.

\section{Reflexión final: un futuro conflictivo e incierto}

En las últimas tres décadas, los conflictos territoriales se han multiplicado en las metrópolis latinoamericanas, debido a la agudización de sus contradicciones y conflictos sociales causados por las prácticas de la acumulación de capital en el neoliberalismo, incluyendo a nuevos actores. De un lado, se colocan los gobiernos locales y el capital inmobiliario-financiero articulados en el proceso de "modernización" urbana tanto en las periferias donde producen los conjuntos de viviendas de interés social, como en las áreas de antigüa urbanización donde llevan a cabo la densificación y verticalización inmobiliaria en los corredores terciarios, los mega-centros comerciales, los conjuntos verticales $u$ horizontales cerrados de vivienda de lujo, las torres de usos mixtos, etcétera; el neoliberalismo económico y las nuevas funciones estatales correlacionadas han reforzado su alianza histórica. Del otro, se sitúan los viejos movimientos urbanos 
populares (MUP) debilitados por el desgaste de sus luchas, el corporativismo de los gobiernos locales, su burocratización, su derivación hacia la gestión de proyectos o la represión; los organismos sindicales, debilitados por las políticas neoliberales y el control estatal, cuando reivindican condiciones urbanas de vida; los nuevos movimientos sociales pluriclasistas ${ }^{9}$ y las organizaciones no gubernamentales (ONG) en cada ámbito de las relaciones económicas, sociales, culturales y territoriales, que se han multiplicado como hongos en las últimas décadas gracias a la ideología individualista propia de la democracia liberal (Pradilla, 2016).

Mientras los MUP aún conservan su carácter popular, los nuevos movimientos sociales y las ONG se caracterizan por la heterogeneidad clasista e ideológica correlativa, incluyendo el conservadurismo, el racismo, etcétera, y en muchos casos, su poca representatividad social real, aunque han obtenido por estas mismas razones el reconocimiento de los actores privados y públicos (Pradilla, 2016). Aunque en ocasiones se alían en función de demandas pluriclasistas o democráticas que atañen a diversas clases sociales, se fragmentan cuando las luchas ocurren por asuntos propios de una clase asocial específica, y cuando esto ocurre pueden actuar solos 0 aún en posiciones encontradas.

A pesar de la elevada urbanización alcanzada por la vida económica y social, la esfera política no la ha reconocido; aún es muy limitado el número de organizaciones y de actores políticos que incluyen en sus programas y plataformas electorales los asuntos urbanos; después de la época de florecimiento de las propuestas de reforma urbana (1960 a 1980), el tema urbano, necesariamente totalizante, ha perdido rentabilidad política, lo que lleva a que en el poder local se adopten políticas urbanas pragmáticas, puntuales y dispersas, sectoriales, coyunturales, alejadas de cualquier proyecto futuro de ciudad que pueda ser aplicado como totalidad, aún en los casos de partidos y políticos "progresistas" o "de izquierda" (Pradilla, 2009, cap. V). El futuro de las ciudades latinoamericanas, las grandes metrópolis en particular, se presenta ante nosotros como muy contradictorio y conflictivo en términos de los intereses urbanos de las clases populares, y muy incierto debido a la debilidad de las fuerzas sociales y políticas que pugnan por su transformación.

Asistimos al renacimiento, a nuestro juicio tardío, de la consigna del derecho a la ciudad formulada por Henri Lefebvre en 1968 como el que asiste a los trabajadores para construir, apropiarse y disfrutar de una ciudad nueva y diferente a la producida por el capitalismo, para lo cual debe llevar a cabo la revolución urbana (Lefebvre, [1970] 1972); en palabras del autor: "Imposible concebir la reconstitución de una ciudad antigua; solo es posible la construcción de una nueva ciudad, sobre nuevas bases, a otra escala, en nuevas condiciones, en otra sociedad." (Lefebvre, [1968] 1969, p. 125). Sin embargo, al popularizarse, la consigna ha perdido en muchos casos su fuerza transformadora inicial, para irse limitando a la reivindicación del usufructo y la participación en la ciudad capitalista actual (Coalición, 2008), hasta hacer posible su entrada en un documento tan gubernamental, neoliberal y homogeneizado como la Nueva Agenda Urbana de las Naciones Unidas de 2016 (ONU-Habitat, 
2016); pero tenemos que reconocer que muchos luchadores urbanos conscientes, consecuentes y decididos levantan esta demanda en sus luchas.

Hoy en América Latina debemos ser conscientes de que tenemos que reconstruir nuestro trabajo para dar fuerza al objetivo de conquistar el derecho a una ciudad nueva y diferente a la capitalista neoliberal, a la construcción de una totalmente distinta sobre nuevas bases planteadas por nuestras clases populares, sus necesidades e intereses. Para ello, como condición necesaria, aunque no suficiente, deberíamos orientar nuestro análisis hacia la sistematización de sus parámetros para que sirvan de punto de partida hacia la formulación de un proyecto de ciudad futura que sirva al movimiento social, y se convierta en el objetivo de las organizaciones políticas, y de las políticas urbanas cuando lleguen al poder en lo local o nacional. Hay que refundar la utopía urbana, para que oriente nuestro trabajo y las reivindicaciones de los trabajadores.

\section{[I] https://orcid.org/0000-0001-9607-8387}

Universidad Autónoma Metropolitana, Unidad Xochimilco, Departamento de Teoría y Análisis, División de Ciencias y Artes para el Diseño. Xochimilco, México.

epradillacrm@hotmail.com

\section{Notas}

(1) En México, en 2013, se aprobaron en el Congreso Federal las "reformas estructurales" a la legislación laboral, a la de energéticos que abrió las puertas al capital privado nacional y extranjero en hidrocarburos y electricidad, la educativa, la fiscal, la de telecomunicaciones, propuestas por el gobierno neoliberal de Enrique Peña Nieto y su Partido Revolucionario Institucional, iniciador de las reformas en 1983.

(2) Empleo estable, mejor remunerado y con prestaciones sociales de ley, en particular las más importantes: la seguridad social y el derecho formal al acceso a la vivienda.

(3) Otra parte está representada por trabajadores de micro y pequeñas empresas o, aún, de grandes empresas industriales, comerciales y de servicios, incluyendo subcontratistas, vinculados laboralmente por medio de formas fuera de la legalidad vigente en términos de horarios, salarios, ausencia de contrato, etc. 
(4) En diferentes momentos (2004, 2008 y 2012), hemos publicado estudios empíricos realizados por grupos de investigación sobre la existencia y características de estos corredores terciarios urbanos y su relación con la multiplicación de centros comerciales en la Zona Metropolitana del Valle de México. También, hemos observado directamente su existencia en otras ciudades mexicanas (Monterrey, Guadalajara, Cuernavaca, Puebla, Querétaro) y metrópolis del continente como Sao Paulo, Río de Janeiro, Bogotá, Quito y Buenos Aires.

(5) Torres o unidades de vivienda cerradas, dotadas de servicios de abasto, infraestructura recreativa y de trabajo, y otras "amenidades" encaminadas a evitar que sus habitantes tengan que salir de su ámbito para desarrollar su vida cotidiana "en condiciones de seguridad y con sus iguales de clase".

(6) Empresas aéreas, cadenas hoteleras, agencias de turismo, casas de cambio, páginas de venta de boletos de avión u otros transportes, reservaciones de hotel y viviendas, cadenas de restaurantes y de espectáculos recreativos, y muchas otras actividades ligadas al sector.

(7) Ciudades informacionales, globales, competitivas, sustentables, resilientes, seguras, del conocimiento, educadoras, incluyentes, compactas, etc.

(8) Políticas urbanas en su sentido amplio, definido en Pradilla (2009, pp. 196 y ss).

(9) Feministas o de género, ambientalistas y ecologistas, de defensa de derechos humanos, o contra la violencia, de libertades civiles, etc.

\section{Referencias}

AGENCIA DE NOTICIAS U.N. (2014). Reprimarización económica promueve extractivismo en América Latina. Bogotá/Colombia, Universidad Nacional de Colombia. Disponible en: http:// agenciadenoticias.unal.edu.co/detalle/article/reprimarizacion-economica-promueveextractivismo-en-latinoamerica.html. Acceso en: 19 jun 2018.

CARRIÓN, F. y PONCE, P. (coords.) (2015). El giro a la izquierda: los gobiernos locales de América Latina. México DF, México, Fundación Friedrich Ebert / 5a Avenida Editores / Café de las ciudades / UAM.

CASABON, C. (2017). La economía informal de América Latina supera por primera vez la de África Subsahariana. World Economic Forum. Disponible en: https://www.weforum.org/es/ agenda/2017/05/la-economia-informal-de-africa-esta-retrocediendo-mas-rapido-que-laeconomia-latinoamericana/. Acceso en: 30 maio 2018.

CASTILLO DE HERRERA, M. y PRADILLA COBOS, E. (2015). La informalidad como concepto ideológico y las formas de subsistencia de la superpoblación relativa en América Latina. In: II SEMINARIO INTERNACIONAL LA FASE ACTUAL DEL CAPITALISMO Y LA URBANIZACIÓN EN AMÉRICA LATINA: lo general y lo particular. Red Latinoamericana de Investigadores sobre Teoría Urbana y Escuela de Planeación Urbano-Regional, Facultad de Arquitectura, Universidad Nacional de Colombia. Medellín, Colombia, febrero de 2015. 
COALICIÓN INTERNACIONAL PARA EL HABITAT, Oficina Regional para América Latina (eds.) (2008). El derecho a la ciudad. Compilación de documentos relevantes para el debate. México DF, México, HIC-AL.

COMISIÓN ECONÓMICA PARA AMÉRICA LATINA Y EL CARIBE (CEPAL) (2017). CEPALSTAT. Bases de datos y publicaciones estadísticas. Santiago de Chile, Cepal - ONU. Disponible en: http://estadisticas. cepal.org/cepatlstat. Acceso en: 18 jun 2018.

(2018). Panorama social de América Latina 2017. Santiago de Chile, Cepal-ONU.

CONNOLLY, P. (2013). “La ciudad y el hábitat popular: Paradigma latinoamericano”. In: RAMÍREZ VELÁZQUEZ, B. R. y PRADILLA COBOS, E. (comps.). Teorías sobre la ciudad en América Latina. México DF, México, Universidad Autónoma Metropolitana.

DEMATTEIS, G. (1998). "Suburbanización y peri urbanización. Ciudades anglosajonas y ciudades latinas". In: MONCLÚS, F. J. (ed.). La ciudad dispersa. Suburbanización y nuevas periferias. Barcelona, España, Centre de Cultura Contemporánea de Barcelona.

DUHAU, E. y GIGLIA, A. (2008). Las reglas del desorden: habitar la metrópoli. México DF, México, Siglo XXI Editores.

DUHAU, E. (2013). "La investigación urbana y las metrópolis latinoamericanas". In: RAMÍREZ VELÁZQUEZ, B. R. y PRADILLA COBOS, E. Teorías sobre la ciudad en América Latina. México DF, México, Universidad Autónoma Metropolitana.

GAUSSEUS, P. (2015). Tomar el poder sin cambiar el mundo. México DF, México, Yecolti Editorial / PRODECUC A.C.

GUILLÉN ROMO, H. (1997). La contrarrevolución neoliberal. México DF, México, Era.

HERREROS, S. y DURÁN LIMA, J. (2011). Reprimarización y desindustrialización en América Latina, dos caras de la misma moneda. Montevideo, Uruguay, Cepal-ONU. Disponible en: https://www. cepal.org/sites/.../presentacion_sebastian_herreros_y_jose_duran.pdf. Acceso en: 18 jun 2018.

JARAMILLO, S. (2009). Hacia una teoría de la renta del suelo urbano. Bogotá, Colombia, Universidad de los Andes.

JORDÁN, R.; RIFFO, L. y PRIETO, A. (coords.) (2017). Desarrollo sostenible, urbanización y desigualdad en América Latina y el Caribe. Santiago de Chile, Cepal-ONU/Cooperación Alemana.

LEFEBVRE, H. ([1968] 1969). El derecho a la ciudad. Barcelona, España, Península.

[1970] 1972). La revolución urbana. Madrid, España, Alianza.

MANRIQUE, L. E. (2006). De la conquista a la globalización. Estados, naciones y nacionalismos en América Latina. Madrid, España, Estudios de Política Exterior S.A.

MARICATO, E. (2015). "La política urbana del Partido de los Trabajadores en el Brasil. De la utopía al impasse". In: CARRIÓN, F. y PONCE, P. (coords.). El giro a la izquierda: los gobiernos locales de América Latina. México DF, México, Fundación Friedrich Ebert / 5ạ Avenida Editores / Café de las ciudades / UAM.

MÁRQUEZ LÓPEZ L. y PRADILLA COBOS E. (2008). Desindustrialización, terciarización y estructura metropolitana: un debate conceptual necesario. Cuadernos del CENDES, n. 69. Caracas, Cendes, UCV. 
MÁRQUEZ LÓPEZ, L. y PRADILLA COBOS, E. (2016). Los territorios latinoamericanos en la mundialización del capital. Territorios, n. 34. Bogotá.

(2017). "La privatización y mercantilización de lo urbano". In: HIERNAUX-NICOLÁS, D. y GONZÁLEZ-GÓMEZ, C. I. La ciudad latinoamericana a debate. Perspectivas teóricas. Querétaro, México, Universidad Autónoma de Querétaro.

MONTERO, L. y GARCÍA, J. (eds.) (2017). Panorama multidimensional del desarrollo urbano de América Latina y el Caribe. Santiago de Chile, Cepal-ONU/Cooperación Regional Francesa para América Latina.

OFFE, C. [1988] (1991). Contradicciones en el Estado del bienestar. México DF, México, Conaculta/ Alianza Editorial.

ONU - HABITAT (2016). Nueva Agenda Urbana, ONU Habitat. Disponible en: http://habitat3.org/wpcontent/uploads/NUA-Spanish.pdf. Acceso en: 7 maio 2018.

OROZCO, C. (2016). ¿Reprimarización en la periferia? El caso brasileño. Papeles de Europa, v. 20. n. 1. España. Disponible en https://www.researchgate.net/publication/312929584_Reprimarizacion_ En_La_Periferia_El_Caso_Brasileno_2003-2013. Acceso en: 21 maio 2018.

PALACIO MUÑOZ, V. H. y VALENZUELA FEIJOO, J. C. (coords.) (2013). Crisis neoliberal y alternativas de izquierda en América Latina. México DF, México, Partido de la Revolución Democrática.

PIRES DO RIO CALDEIRA, T. (2007). Ciudad de muros. Barcelona, España, Gedisa.

PRADILLA COBOS, E. (1984). Contribución a la crítica de la "teoría urbana". Del espacio" a la "crisis urbana". México DF, México, Universidad Autónoma Metropolitana, Xochimilco.

(1998). Metrópolis y megalópolis en América Latina. Diseño y Sociedad, n. 8. México DF, Universidad Autónoma Metropolitana, Xochimilco.

(2009). Los territorios del neoliberalismo en América Latina. México DF, México, Miguel Ángel Porrúa Editor / Universidad Autónoma Metropolitana, Xochimilco.

(2010a). Teorías y políticas urbanas: ¿Libre mercado mundial o construcción regional? Revista Brasileira de Estudos Urbanos e Regionais, v. 12. n. 2. Sao Paulo.

(2010b). Mundialización neoliberal, cambios urbanos y políticas estatales en América Latina. Cadernos Métropole, n. 24. São Paulo.

(2013). Formas productivas, fracciones del capital y re-construcción urbana en América Latina. México DF, México, Inédito.

(2014). La ciudad capitalista en el patrón neoliberal de acumulación de capital. Cadernos Métropole, n. 31. São Paulo.

(2015). De la ciudad compacta a la periferia dispersa. Ciudades, n. 106. Puebla.

(2016). "Las transformaciones de los conflictos y los movimientos sociales en las ciudades latinoamericanas". In: CARRIÓN, F. y ERAZO, J. (coords.). El derecho a la ciudad en América Latina. Visiones desde la política. Ciudad de México, México, PUEC-UNAM/IDRC-CRDI.

(coord.) (2016). Zona Metropolitana del Valle de México: cambios demográficos, económicos, y territoriales. Libro electrónico, México DF, México, Universidad Autónoma Metropolitana. Disponible en: www.casadelibrosabiertos.uam.mx/index.php/libro-electronico 
PRADILLA COBOS, E. y MÁRQUEZ LÓPEZ, L. (2007). Presente y futuro de las metrópolis de América Latina. Cadernos Metrópole, n. 18. São Paulo.

RAMÍREZ VELÁZQUEZ, B. R. y PRADILLA COBOS, E. (coords.) (2013). Teorías sobre la ciudad en América Latina. México DF, México. Universidad Autónoma Metropolitana.

ROBINSON, W. I. [2008] (2015). América Latina y el capitalismo global. Una perspectiva crítica de la globalización. México DF, México, Siglo XXI.

SALAMA, P. (2012). Globalización comercial: desindustrialización prematura en América Latina e industrialización en Asia. Comercio Exterior. v. 62, n. 6. BANCOMEXT, México.

VALENZUELA AGUILERA, A. (coord.) (2011). Ciudades seguras. México DF, México, Universidad Autónoma del Estado de México / Miguel Ángel Porrúa Editor.

(2016). La construcción espacial del miedo. México DF, México, Universidad Autónoma del Estado de Morelos y Juan Pablos Editor.

VALENZUELA FEIJOO, J. C. (2013). “América Latina: alternativas frente a la crisis neoliberal”. In: PALACIO MUÑOZ, V. H. y VALENZUELA FEIJOO, J. C. (coords.). Crisis neoliberal y alternativas de izquierda en América Latina. México DF, México, Partido de la Revolución Democrática.

Texto recebido em 22/jul/2018

Texto aprovado em 10/set/2018 